\title{
Hypoglycaemia unawareness and the brain
}

\author{
D. Smith, S. A. Amiel \\ Guy's, King's and St Thomas' School of Medicine, London, UK
}

\section{Abstract}

The intention of this paper is to critically review the current state of knowledge of the role of the brain in the syndrome of hypoglycaemia unawareness.

Both the role of the brain in the detection of hypoglycaemia and initiation of the counterregulatory responses and the function of the cerebral cortex during acute hypoglycaemia are considered. The evidence for and against the brain as the primary site of mammalian hypoglycaemia sensing and the mechanisms whereby such sensing may occur and change in hypoglycaemia unawareness are discussed.
Current evidence supports a major role for the central nervous system in hypoglycaemia sensing and there is increasing understanding of the mechanisms of counterregulatory failure and cognitive dysfunction in hypoglycaemia unawareness. More needs to be done to expand this understanding and translate it into therapeutic strategies to defend against severe hypoglycaemia in diabetes therapy. [Diabetologia (2002) 45:949-958]

Keywords Hypoglycaemia, cognitive function, counterregulation, diabetes mellitus, positron emission tomography, brain glucose uptake, catecholamines.
Iatrogenic hypoglycaemia was described in the very first days of insulin therapy and hypoglycaemia without subjective awareness was described shortly thereafter. The British pioneer of diabetes therapy, R.D. Lawrence, himself diabetic, gave a clear account of neuroglycopenic hypoglycaemia with reduced subjective awareness more than 60 years ago [1]. Over 20 years ago the site of coordination of glucoregulatory responses was located in the hypothalamus [2].

Hypoglycaemia sufficient to cause clinically significant cortical dysfunction does not occur in healthy

Received: 15 January 2002 / Revised: 24 April 2002

Published online: 8 June 2002

(C) Springer-Verlag 2002

Corresponding author: S.A. Amiel, MD, Guy's, King's and St Thomas' School of Medicine, King's College, Denmark Hill Campus, Bessemer Rd., London, SE5 9PJ, United Kingdom, E-mail: stephanie.amiel@kcl.ac.uk

Abbreviations: EGP, Endogenous glucose production; VMH, ventromedial hypothalamus; UKPDS, United Kingdom Prospective Diabetes Study. subjects. As blood glucose decreases, pancreatic insulin secretion decreases and glucagon secretion increases, stimulating endogenous glucose production and slowing the blood glucose fall. Later, sympathetic activation and catecholamine secretion, with release of growth hormone and adrenocorticotrophin, driving release of adrenal cortical steroids, contribute by supporting endogenous glucose production and reducing consumption of glucose by peripheral tissues. An associated complex of symptoms, including hunger, encourages an eating response. The functional anatomy of these responses indicate a central coordinating structure involving the regions around the hypothalamus, hippocampus and caudate nuclei. Failure of some or all of these counterregulatory mechanisms allows a more severe decrease in plasma glucose concentrations, resulting in cortical dysfunction. Thus counterregulatory failure is associated with impaired awareness of hypoglycaemia and an increased risk of severe hypoglycaemia, in which cognitive function is so disturbed that the patient can become drowsy, unco-ordinated, confused or even comatose. This is a 
considerable clinical problem in the pharmacological treatment of diabetes mellitus. This paper will review some of the current literature describing the brain's involvement in the mechanisms of control of glucose homeostasis and what can go wrong in patients with diabetes treated pharmacologically. In particular, we will focus on the current state of knowledge of hypoglycaemia sensing and the initiation of the protective counterregulatory responses and the cognitive events of acute hypoglycaemia.

\section{The physiological defences against severe hypoglycaemia in diabetes}

The neuroendocrine responses to hypoglycaemia begin at an arterial plasma glucose concentration just under $4 \mathrm{mmol} / \mathrm{l}$, with a reduction in insulin secretion and a stimulation of pancreatic glucagon. The reduction of insulin secretion may be a local response and there is good evidence to show that factors locally within the pancreas are also crucial to the glucagon response. How glucagon-secreting alpha cells detect and respond to alterations in circulating glucose concentration is not clear, but that their action is in some sense dependent upon the insulin secretory response of the local beta cells is made evident by the diminution of glucagon responses to acute hypoglycaemia in the presence of sulphonylureas [3, 4]. It is thought that the sulphonylureas, acting through their specific receptors on the beta cell, support the concentrations of insulin within the islet, the corollary being that glucagon secretion is, at least in part, secondary to a reduction in beta-cell insulin secretion. Certainly, although the data are incomplete, loss of glucagon responses to acute hypoglycaemia correlates well with loss of C-peptide secretion and is found in patients with advanced Type II (non-insulin-dependent) diabetes mellitus and Cpeptide negative Type I (insulin-dependent) diabetes mellitus within the first five years of the disease $[5,6$, 7] and perhaps in late onset Type II diabetes [8], at the insulin requiring stage. Nevertheless, there is also evidence for central involvement in the glucagon response, via activation of the sympathetic and parasympathetic nervous systems [9].

Compared to the responses of the pancreatic hormones, sympathetic stimulation and adrenaline secretion start at slightly deeper degrees of hypoglycaemia and have peripheral as well as direct hepatic actions. Both are under neurological control, and they act to support circulating glucose concentrations by stimulation of glycogenolysis and gluconeogenesis both directly and indirectly. An important part of the actions of the sympathetic nervous system and adrenaline is the peripheral enhancement of lipolysis, releasing non-esterified fatty acids. These provide substrates for gluconeogenesis and also diminish insulin-stimulated peripheral glucose uptake [10]. Glutamine uptake is also enhanced, although proteolysis is not increased [11]. Cortisol and growth hormone responses, which are important in the long-term maintenance of blood glucose concentrations, occur after more prolonged or a severe decrease in circulating glucose concentrations, as their release is secondary to hypothalamic activation $[12,13,14]$, and their action on peripheral glucose metabolism and gluconeogenesis is also delayed and prolonged. In experimental models where hormonal responses are measured during stepped slow reduction of plasma glucose, it seems as though the cortisol and growth hormone are responding to a lower plasma glucose than the catecholamine responses but this could be a feature of their slower initiation and a late response to an earlier higher glucose concentration. All these responses to hypoglycaemia, sympathetic activation, adrenaline, cortisol and growth hormone, are clearly centrally mediated, involving as they must the sympathetic centres and the hypothalamic-pituitary-adrenal axis. They all lead to reduced peripheral glucose utilisation as well as enhanced endogenous glucose production, so the net result is to restore circulating glucose concentrations, helped by the symptom-driven ingestion of food.

Endogenous glucose production (EGP) was previously believed to be exclusively a hepatic response but recent studies involving selective catheterisation to calculate net glucose output from kidney from blood flow and arteriovenous-glucose difference data indicate that renal gluconeogenesis could contribute to overall EGP during hypoglycaemia. Such studies indicate that renal gluconeogenesis is sensitive to insulin [15] and responds to both catecholamines [16] and hypoglycaemia [17]. A recent study in humans confirmed the potential for renal involvement in human peripheral glucose metabolism by showing sustained glucose production during the anhepatic phase of liver transplantation [18].

\section{Hypoglycaemia in diabetes - a failure of counterregulation}

Because of the importance of the reduction in insulin secretion at the onset of hypoglycaemia in defending against more severe hypoglycaemia, any circumstance that can maintain circulating insulin concentrations during decreasing blood glucose supply creates a risk of hypoglycaemia. The pharmacological management of diabetes with agents that enhance insulin secretion independently of blood glucose such as the sulphonylureas or with exogenous insulin itself immediately creates a risk of hypoglycaemia as blood insulin concentrations are no longer under endogenous control. As seen in the Type II diabetic patients of the United Kingdom Prospective Diabetes Study (UKPDS) [19], the risk is greater with exogenous insulin than with insulin secretagogues, perhaps because of the insulin 
regimen itself but possibly because the latter enhance insulin delivery direct to the liver, while exogenous insulin is delivered into the peripheral circulation. Support for this concept comes from the evidence of lower hypoglycaemia rates in patients using intra-peritoneal routes of insulin delivery and, conversely, the description of hypoglycaemic events in recipients of whole organ pancreas transplants, drained into the systemic circulation $[20,21,22]$. However, from the brief description of the other components of the counterregulatory response above, it follows that severe hypoglycaemia, low enough to cause clinically relevant cognitive impairment, can generally only occur if two events coincide - artificial increase of insulin concentrations and failure of the other parts of the counterregulatory response. Loss of glucagon responsiveness could be enough, and certainly C-peptide negativity is a recognised association of increased risk of severe hypoglycaemia. Progressive loss of endogenous insulin secretory capacity during the progression of Type II diabetes might explain the low rate of severe hypoglycaemia rates in Type II diabetic patients treated with insulin in the UKPDS, compared to much higher rates of insulin treated Type II patients in a community study. The former were newly diagnosed at the start of the study. The later would have been started on insulin later in the course of their disease, as a result of progressive failure to control the blood glucose with oral agents $[19,23]$. The patients in the second study, therefore, could have been considerably more insulin deficient than in those of the UKPDS and could therefore have also lost glucagon responsiveness.

A much greater risk of severe hypoglycaemia correlates with the failure of the other counterregulatory responses. Thus diabetic patients with a history of recurrent severe hypoglycaemia show an inability to sustain glucose concentrations in the presence of low dose insulin infusion insufficient to cause major hypoglycaemia in healthy peers [24]. Indeed, nearly 20 years ago it was suggested that the failure to maintain a reasonable plasma glucose in the presence of a lowdose insulin infusion might be used to predict a particularly high risk of severe hypoglycaemia in diabetic patients about to start intensified insulin [25]. More severe hypoglycaemia will elicit a full neuroendocrine response in all patients but by then the cortical dysfunction might also be severe. There is little doubt now that the defect is one of glucose sensing.

\section{Glucose sensing in hypoglycaemia}

The concept of central control of glucose metabolism was established by Claude Bernard. Picure diabetes is the hyperglycaemia which results from a lesion of the hypothalamus. It is teleologically appealing to place the principal hypoglycaemia sensor in the brain, as glucose supplies to the brain are so critical for brain function. It is also appealing to place the centres controlling the response to acute hypoglycaemia (seen in extremes only in pathology or therapeutics) close to or with the centres regulating appetite and food intake.

Portal vein glucose sensing. There are glucose sensors in other body regions. The archetypal glucose sensor must be the pancreatic beta cell, with its exquisitely glucose-sensitive insulin secretory capacity. Glucose sensing can also occur in the portal vein draining the gastrointestinal tract to the liver. The cells in this region contain the beta-cell glucose transporter GLUT 2 [26]. Amelioration of the hormonal responses to systemic hypoglycaemia by the preservation of glucose supplies to the portal vein has been demonstrated in animals (e.g. [27]). The same group of investigators showed that the portal glucose signal requires an intact vagus [28] but these data remain controversial $[29,30]$. Other capsacin-sensitive afferent nerve pathways could be involved [31]. The portal vein glucose sensors are of course ideally placed to monitor glucose entrance to the circulation from the gastrointestinal tract and it could be the creation of a glucose concentration gradient between the portal and arterial circulation that creates a neurological signal. Such a portal signal has been implicated in the control of net hepatic glucose uptake [32], food intake [33], and tissue glucose utilisation [26]. In humans, hepatic-portal denervation is associated with a small reduction in the adrenaline responses to insulin infusion [34], although a small mismatch in the hypoglycaemic profiles makes these data difficult to interpret. One recent report has failed to find any loss of hormonal response to hypoglycaemia after oral glucose administration, which argues against a major role for portal vein glucose sensing in the control of the human responses to acute hypoglycaemia, at least once the centrally mediated responses have started [35].

Central nervous system glucose sensing. The data supporting a major hypoglycaemia sensor in the region of the cerebral and/or vertebral artery circulations are strong. A decade ago, a group carried out a series of selective catheterisation studies in which counterregulatory responses to systemic hypoglycaemia were aetiolated by maintaining glucose supplies to the cerebral and vertebral circulation $[36,37]$. Similar studies by other investigators came to different conclusions but their data also showed some reduction in adrenaline responses to systemic hypoglycaemia with brain glucose infusion $[38,39]$.

How might the central nervous system act as an hypoglycaemia sensor and co-ordinator of counterregulation? One study concluded that multiple areas of the mammalian brain might be involved in glucose sensing [37]. This interpretation gains credence from more recent animal work using c-fos expression to show activation of networks of neurones by de-oxyglucose in- 
duced glucoprivation, primarily in the hind brain of rats, with connections to centres in the hypothalamus and medulla [40].

Others have now clearly delineated populations of neurones that uniquely use glucose as a signalling molecule, rather than a metabolic substrate, altering their firing rate in response to changes in ambient glucose supply, rather than their metabolism [41]. Subpopulations of these neurones respond either to decreasing blood glucose concentrations (the glucosesensitive neurones) or to increasing blood glucose concentrations (the glucose-responsive neurones). It is likely that the changes in response to hypoglycaemia in different clinical settings involve alterations in neurotransmission and neuro-excitation as much as a simple relation between glucose supply and neuronal metabolism. The number of studies on this complex area are increasing rapidly. Although it is beyond the scope of this review, it might be useful to mention a few points that could become clinically relevant over the next few years. In particular it is important to illustrate the likely complexity of hypoglycaemia sensing and to realise the probable involvement of a range of neurotransmitters and CNS hormones in the regulation of the corrective response. Changes in glucose have been shown to influence neuronal release of several neurotransmitters, including dopamine and GABA $[42,43]$ and CNS hormones involved in food intake and appetite regulation such as neuropeptide Y [44] and catecholamines [40]. Hypothalamic dopaminergic neurones in particular can regulate secretion of many of the counterregulatory hormones and are stimulated by glucoprivation [45].

The glucose sensing neurones may use molecular mechanisms akin to those used by the pancreatic beta cell to sense blood glucose concentrations and coordinate glucoregulatory responses. There are reports of both glucokinase [46] and GLUT-2 [47]. Furthermore, neurones expressing sulphonylurea receptor and potassium ATP channel complexes have been identified spread widely throughout the brain [48] and in vitro neurones from a variety of sites have been shown to alter neurotransmitter release in response to agents that open and close the potassium ATP channels [43, 49]. All these data have been acquired from studies in laboratory animals and must be applied to humans with caution. The involvement of these pathways in human hypoglycaemia counterregulation is being examined, however, using studies in people with known defects in the relevant molecules [50, 51].

Although the trigger for counterregulation is a decrease in blood glucose supply to the hypoglycaemia sensors, the mechanism whereby the responses are activated is likely to be the ensuing fall in intracellular metabolism. Counterregulatory responses to progressive acute hypoglycaemia in human subjects are delayed at onset and reduced in magnitude by provision of non-glucose substrates for metabolism such as $\beta$ - hydroxybutyrate or lactate, and to some extent, nonesterified fatty acids and glycerol [52, 53, 54]. The ability of such fuels also to delay and diminish the cortical dysfunction of acute hypoglycaemia is compatible with, although not conclusive evidence for, locating the hypoglycaemia sensor in the brain $[53,55]$.

\section{The clinical problem of counterregulatory failure in the treatment of diabetes mellitus}

In general, a diabetic patient is protected from severe hypoglycaemia by residual endogenous central mechanisms described above and most particularly by the perception of associated symptoms at an early stage of the plasma glucose decrease, before the circulating glucose concentrations are too low to support a coordinated and logical feeding response [56]. In diabetes, these important symptoms of hypoglycaemia can be activated at quite high plasma glucose concentrations, especially if there has been chronic hyperglycaemia $[8$, 57]. In Type II diabetes, where there is presumably no previous exposure to hypoglycaemia, even patients considered to have acceptable glycaemic control activate counterregulatory hormone responses at nonhypoglycaemic glucose concentrations [58]. Clinical problems arise when the symptomatic responses are impaired and this is generally associated with a failure of the endogenous hormonal responses to hypoglycaemia. Patients with diabetes who fail to generate subjective awareness of early hypoglycaemia have a threefold increase in risk of severe hypoglycaemia - hypoglycaemia in which cognitive function is impaired [59]. The typical associations are in Type I diabetes, with previous history of severe hypoglycaemia [24], long duration of diabetes [60] and most topically, intensification of insulin therapy as shown by the Diabetes Control and Complications Trial (DCCT) to be able to reduce the onset of microvascular complications by up to $76 \%$ [61]. In the DCCT, random allocation to intensified insulin therapy was associated with a threefold increase in the incidence of severe hypoglycaemia, a similar increase to that of asymptomatic hypoglycaemia reported some years before with early insulin pump therapy [62]. The aetiology of the syndrome of hypoglycaemia unawareness and increased risk of severe hypoglycaemia in intensively treated Type I diabetic patients is similar to that reported for Type I diabetic patients with recurrent severe hypoglycaemia referred to above, namely a failure of glucose counterregulation. Intensively treated, tightly controlled Type I diabetic patients were not able to sustain plasma glucose concentrations above those associated with cognitive impairment in the presence of low dose insulin infusion [63]. This was later shown to be associated with a lower level for the onset of the hormonal and symptomatic responses to acute hypoglycaemia [64]. The defect is therefore one of glucose sensing, with the 
counterregulatory responses to hypoglycaemia triggered at different glucose concentrations.

Probably the most important factor in determining the plasma glucose concentration for initiating any glucose counterregulatory response is the person's previous glycaemic experience. We have already commented on the relatively high glucose concentrations associated with the onset of counterregulatory responses in chronically hyperglycaemic groups of subjects. In Type II diabetic patients poorly controlled on oral agents, the exaggerated and vigorous hormonal and symptomatic responses can be damped down to normal by intensifying diabetes treatment with insulin [8]. This could be because of normalisation of antecedent glycaemia but could also relate to intermittent exposure to hypoglycaemia in the course of the intensified therapy. The effect is more dramatic in Type I patients going onto intensified insulin therapy, where the plasma glucose concentration for counterregulatory hormone and symptom responses is depressed to well below normal, perhaps because of the tighter control achieved in these patients or because of a greater exposure to hypoglycaemia during their tightening of control [65]. Certainly, counterregulatory delay, similar to that shown in the hypoglycaemia-unaware diabetic patient can be induced, at least transiently, in healthy volunteers and hypoglycaemiaaware diabetic volunteers by prior exposure to plasma glucose concentrations for 2 to $4 \mathrm{~h}$ between 2.8 and $3.8 \mathrm{mmol} / \mathrm{l}[66,67,68,69,70]$. Most tellingly, patients with diabetes, a history of recurrent severe hypoglycaemia, hypoglycaemia unawareness and counterregulatory failure respond to a period of hypoglycaemia avoidance with restoration of symptomatic and hormonal responses to induced hypoglycaemia. This has now been shown in patients with short-term and long-term diabetes and is also seen in patients in whom the original counterregulatory failure was not associated with strict metabolic control [71, 72]. There is a further defect in diabetic patients with hypoglycaemia unawareness and a high risk of severe hypoglycaemia - namely an apparent loss of sensitivity to sympathetic stimulation [73, 74]. This too could be reversible by strict hypoglycaemia avoidance and could explain a study in which subjective awareness of hypoglycaemia, but not hormonal responsiveness, was restored in hypoglycaemiaunaware Type I diabetic patients by hypoglycaemia avoidance [75]. In any event, the critical circulating glucose concentration to be avoided for problems with hypoglycaemia-sensing could be about $3 \mathrm{mmol} / \mathrm{l}$ on home glucose monitoring [72]. It should be noted that diabetic autonomic neuropathy probably does not impair glucose counterregulation and hypoglycaemia awareness as expected. Although the neuronal and hormonal activation might be less, there could be increased sensitivity to the activation that does occur, presumably conferring some degree of protection [24, 60, 76, 77, 78, 79].

From the above, it has been concluded that a major defect in counterregulatory failure is a failure of hypo- glycaemia sensing. Brain hypoglycaemia sensing has naturally been the focus of attention. An initial hypothesis was that exposure to recurrent hypoglycaemia during diabetes therapy could underlie the failure of counterregulation. Certainly, conventional insulin therapy results in frequent and often undetected exposure to blood glucose concentrations of less than $3 \mathrm{mmol} / \mathrm{l}$. Measuring blood glucose hourly overnight in Type I diabetic children on conventional, twice daily mixed insulin therapy, showed hypoglycaemia (defined as a blood glucose less than $3.5 \mathrm{mmol} / \mathrm{l}$ in almost half of them on each of two nights of monitoring, with a median blood glucose $1.9 \mathrm{mmol} / \mathrm{l}$ and a median duration of $270 \mathrm{~min}$ ) [80]. Early experience with continuous glucose monitoring also suggests insulin-treated Type I diabetic patients could be experiencing much more hypoglycaemia than is detected either by themselves or by conventional intermittent home blood glucose monitoring [81].

\section{Potential mechanisms of failure of central glucose counterregulation}

Glucose transporters. It has long been known that severe prolonged hypoglycaemia can enhance glucose uptake into the brain in experimental animals. More recently it has been shown that, in vitro, transcription and/or translation and expression of both GLUT-1 (the endothelial glucose transporter protein) and GLUT-3 (the neurone specific glucose transporter) are increased in response to glucose deprivation [82, 83]. This provides a possible mechanism for counterregulatory failure in diabetes - hypoglycaemia resulting in an up-regulation of brain glucose transport capacity so that intracellular glucose, metabolism and function can be better maintained during subsequent exposure to hypoglycaemia. There are some data to support this hypothesis in humans. Boyle's landmark studies used an arteriovenous difference technique to show enhanced brain glucose uptake during hypoglycaemia in human volunteers after exposure to $56 \mathrm{~h}$ of modest hypoglycaemia and in hypoglycaemia-unaware diabetic subjects with counterregulatory failure $[84,85]$.

In contrast, positron emission tomography (PET) studies of brain glucose uptake and metabolism have failed to show any global change in this parameter in different groups of diabetic subjects with different prior glycaemic experience. Early studies with labelled CO-methyl glucose [86] and a recent study with ${ }^{11} \mathrm{C}$-glucose found no indication of altered brain glucose uptake or metabolism in Type I diabetic patients in poor control or in normal volunteers with counterregulatory deficits after antecedent hypoglycaemia exposure [87]. It is likely that a further adaptation of the intracellular glucose metabolic pathway and the subsequent change in neurotransmitter release is involved in changing the plasma glucose concentrations triggering any reaction 
Fig. 1. Statistical parametric map comparing regional brain uptake of ${ }^{18} \mathrm{~F}$ deoxyglucose across four groups - hypoglycaemia-aware and unaware Type I diabetic men studied at euglycaemia and at hypoglycaemia. The white area shows the brain region where the change in FDG uptake between euglycaemia and hypoglycaemia is different between the hypoglycaemia-aware and unaware diabetic men. Adapted from [93] with permission of the editors of Diabetes sagittal

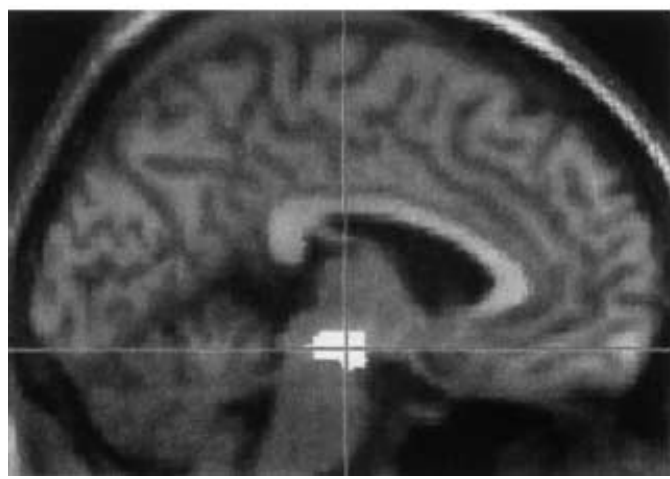

coronal

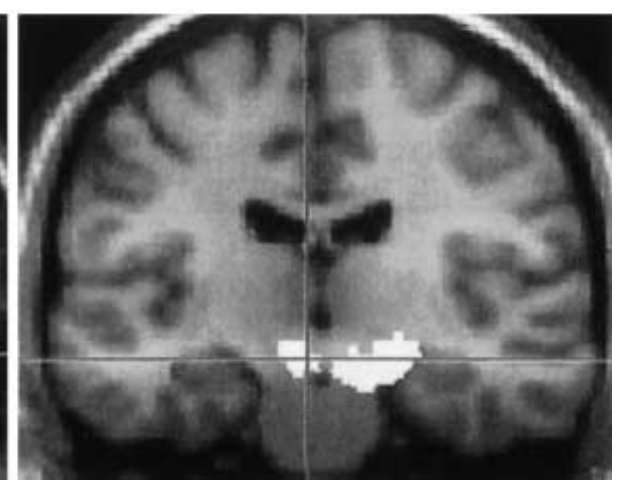

to hypoglycaemia. It is also possible that a regional change in brain glucose handling is involved.

Regional differences in brain glucose handling. It may be stating the obvious but the brain is not an homogenous organ like the liver - it should instead be regarded as a group of organs, all with different if interdependent activities and actions - and metabolic capacities. Different brain functions have different sensitivities to hypoglycaemia. As described above, the activation of the various parts of the hypothalamic and sympathetic centres occur at plasma glucose concentrations ranging from 3.0 and $3.6 \mathrm{mmol} / \mathrm{l}[57,88,89]$, and different parts of the cerebral cortex, investigated as performance of different cognitive function tasks, also show detectable evidence of dysfunction at different glucose concentrations during progressive hypoglycaemia [8, $65,84,85]$. In addition to being differently sensitive to hypoglycaemia per se, different brain tasks have a different ability to alter their sensitivity to hypoglycaemia in hypoglycaemia unaware states. Thus, the sensitivity of symptom generation and the initiation of counterregulatory hormone responses to hypoglycaemia are very susceptible to alteration by changes in prior glycaemic experience. The hypoglycaemia sensitivity of cortical functions on the other hand could be very resistant to change by prior hypoglycaemia experience, as with four-choice reaction time $[8,65]$ or quite sensitive, as with Stroop tasks [84] and memory tasks [71]. Refinements in neuroimaging could help elucidate some of these differences. The brain regions active in the performance of simple tasks can already be imaged by techniques such as functional magnetic resonance imaging and the effects of hypoglycaemia upon such activation being determined [91].

The hypothalamus as the human hypoglycaemia sensor. As first suggested by Claude Bernard, it is very likely that the area of the hypothalamus is critically involved. More recently, others focussed attention on this brain region, when they showed hyperglycaemia in response to injection of the glucoprivic agent de- oxyglucose into the third ventricle of laboratory rats [92]. In a series of studies using microdialysis catheters to alter the glucose milieu of neurones in the ventromedial hypothalamus (VMH) and its environs, a group indicated the critical role of this brain area in mammalian glucose counterregulation. Creating a lesion in the VMH resulted in systemic hyperglycaemia in rats [93], as did creating localised intracellular glucose deficit by injecting deoxyglucose [94], and finally, infusing glucose during systemic hypoglycaemia reduced the magnitude of the catecholamine response to the hypoglycaemia [95]. The molecular basis for these responses could be due to a change in glucose uptake but is likely to be more complex. The glucagon and catecholamine responses to localised $\mathrm{VMH}$ administration of 2 deoxyglucose are diminished in recurrently hypoglycaemic rats, just as the response to hypoglycaemia per se would be expected to be, suggesting an adaptation of glucose processing inside the cell membrane [96]. One concern is the possibility of apoptosis of glucose sensing neurones, in response to hypoglycaemia [97], although earlier animal studies would suggest that hypoglycaemia has to be very severe and/or prolonged to induce irreversible cellular changes. Another implicates the hypothalamic activation of the cortisol pathway during hypoglycaemia in the subsequent suppression of the responses to subsequent hypoglycaemia [98].

Localised cerebral glucoprivation studies cannot be replicated in humans. We have recently shown differences in the handling of the positron-emitting glucose analogue ${ }^{18} \mathrm{~F}$ fluorodeoxyglucose by a central brain region including the hypothalamus between diabetic patients with and without the counterregulatory failure of the hypoglycaemia-unawareness syndrome studied at euglycaemia and hypoglycaemia [99]. Although FDG cannot be used to calculate absolute rates of glucose metabolism in hypoglycaemia, the differences in FDG handling can be calculated and indicate that a change in glucose uptake or metabolism in this specific brain region is involved in the pathogenesis of the syndrome (Fig. 1). The anatomy of central glucose control in hu- 
mans is further illustrated in a case report of a patient with an hypothalamic sarcoid deposit in the hypothalamus whereby the patient had abnormalities of systemic glucose concentration until the deposit was shrunken away by steroid therapy [100]. Parenthetically, the euglycaemic part of the FDG study, like the earlier PET studies using different glucose analogues, gave no indication of a global increase in glucose uptake in the hypoglycaemia-unaware diabetic patients.

\section{The effects of ageing on hypoglycaemia unawareness}

Unheralded loss of cortical function as can occur in diabetic patients with hypoglycaemia unawareness can have devastating physical, social and emotional consequences for the patient and his/her family. It is worth noting that the problem is not exclusively one of young, intensively treated Type I diabetic patients. In one study of presentations to hospital with severe hypoglycaemia of people older than 70 years, nearly all presented with neuroglycopenic symptoms including unconsciousness and confusion [101] and similar data have been reported elsewhere for hypoglycaemia induced by long acting sulphonylureas [102, 103]. Age itself can be a very important factor. A study has shown that neurological symptoms are important in hypoglycaemia in elderly diabetic people [104], and in our own laboratory-based studies, whereas older men showed no diminution of catecholamine responses to induced controlled hypoglycaemia, they reported markedly fewer autonomic symptoms and a greater propensity to visual disturbance and showed a greater slowing of psychomotor performance [105]. At the other end of the scale, children who have more vigorous counterregulatory hormone responses than adults [106], nevertheless seem more likely to present with behavioural and mood disturbances in hypoglycaemia than adults [107]. Severe hypoglycaemia in young children can result in seizure and there is some evidence that this combination in patients younger than 7 years could have effects on intellectual function at their teenage years (e.g. [108]). In adults, there is some evidence that severe hypoglycaemia from which a full recovery seems to be made at the time, or recurrent episodes of confusional hypoglycaemia could have permanent effects on cortical function but the effects in grouped data are very small and can be confounded by continued hypoglycaemia and intercurrent illness, especially of mood, such as depression [109]. A full discussion of the possible long-term brain effects of hypoglycaemia unawareness is outside the scope of this review but cortical responses to recurrent hypoglycaemia might be less plastic and reversible than hypothalamic and glucose sensing functions and more needs to be done to understand the underlying mechanisms.

\section{Conclusions}

Hypoglycaemia unawareness is a problem of, and for, the brain. Current evidence points to a major role for the brain, specifically the hypothalamus, in initiating and controlling the symptomatic and protective responses to acute hypoglycaemia in humans. Failure of these responses increases risk of severe hypoglycaemia with clinically important cortical dysfunction. Although much is now known about the mechanisms of hypoglycaemia sensing and the counterregulatory responses, further work is needed to find ways of enhancing counterregulatory responses and/or supporting cortical dysfunction at times of glucose deprivation. As severe hypoglycaemia is almost always either pathological or iatrogenic, the responses to it can have other functions in physiology, such as control of glucose metabolism in general, feeding responses, appetite, etc. Greater understanding of the mechanisms of glucose sensing and counterregulatory responses could therefore provide relevant information in fields apart from diabetes therapy, although solving the problems of hypoglycaemia unawareness and severe hypoglycaemia in the proper treatment of diabetes is a vital end in itself.

Sources. This review is based on the relevant literature published in the English language during the period 1992-2002 and seminal prior contributions. The sources available to the authors were integrated with sources identified through PubMed searches for specific issues, such as "GLUT 2 and hypoglycaemia", "glucokinase and hypoglycaemia", "positron emission tomography and hypoglycaemia"; or specific authors such as "Levin", "Bolli".

Acknowledgements. The authors wish to thank the Wellcome Trust, the Juvenile Diabetes Foundation International and Diabetes UK for supporting the research that is quoted in this review that is from their own group.

\section{References}

1. Lawrence RD (1941) 19410 Insulin hypoglycaemia. Changes in nervous manifestations. Lancet ii:602-604

2. Berizo CA (1983) Hypothalamus and blood glucose regulation. Life Sciences 32:2509-2515

3. Peacey SR, Rostami-Hodjegan A, George E, Tucker GT, Heller SR (1997) The use of tolbutamide-induced hypoglycemia to examine the intraislet role of insulin in mediating glucagon release in normal humans. J Clin Endocrinol Metab 82:1458-1461

4. Landstedt-Hallin L, Adamson U, Lins PE (1999) Oral glibenclamide suppresses glucagon secretion during insulin-induced hypoglycemia in patients with type 2 diabetes. J Clin Endocrinol Metab 84:3140-3145

5. Muhlhauser I, Overmann H, Bender R, Bott U, Berger M (1998) Risk factors of severe hypoglycaemia in adult patients with Type I diabetes - a prospective population based study. Diabetologia 41:1274-1282 
6. Bott S, Bott U, Berger M, Muhlhauser I (1997) Intensified insulin therapy and the risk of severe hypoglycaemia. Diabetologia 40:926-932

7. Bolli G, DeFeo P, Campugnucci P et al. (1983) Abnormal glucose counterregulation in insulin-dependent diabetes mellitus. Interaction of anti-insulin antibodies and impiared glucagon secretion. Diabetes 32:134-141

8. Korzon-Burakowska A, Hopkins D, Matyka K et al. (1998) Effects of glycemic control on protective responses against hypoglycemia in type 2 diabetes mellitus. Diabetes Care 21:282-291

9. Taborsky GJ Jr, Ahren B, Havel PJ (1998) Autonomic mediation of glucagon secretion during hypoglycemia: implications for impaired alpha-cell responses in type 1 diabetes. Diabetes 47:995-1005

10. Frizzell RT, Hendrick GK, Brown LL et al. (1998) Stimulation of glucose production through hormone secretion and other mechanisms during insulin-induced hypoglycemia. Diabetes 37:1531-1541

11. Battezzati A, Benedini S, Fattorini A, Piceni Sereni L, Luzi L (2000) Effect of hypoglycemia on amino acid and protein metabolism in healthy humans. Diabetes 49:1543-1551

12. De Feo P, Perriello G, Torlone E et al. (1989) Contribution of cortisol to glucose counterregulation in humans. Am J Physiol 257:35-42

13. De Feo P, Perriello G, Torlone E et al. (1989) Demonstration of a role for growth hormone in glucose Am J Physiol 256:835-843

14. De Feo P, Perriello G, Torlone E et al. (1991) Contribution of adrenergic mechanisms to glucose counterregulation in humans. Am J Physiol 261:725-736

15. Meyer C, Dostou J, Nadkarni V, Gerich J (1998) Effects of physiological hyperinsulinemia on systemic, renal, and hepatic substrate metabolism. Am J Physiol 275:915-921

16. Stumvoll M, Chintalapudi U, Periello G, Gutierrez O, Gerich J (1995) Uptake and release of glucose by the human kidney: postabsoprtive rates and responses to epinephrine. J Clin Invest 96:2528-2533

17. Cersosimo E, Molina PE, Abumrad NN (1998) Renal lactate metabolism and gluconeogenesis during insulin induced hypoglycaemia. Diabetes 47:1101-1106

18. Joseph SE, Heaton N, Potter D, Pernet A, Umpleby MA, Amiel SA (2000) Renal glucose production compensates for the liver during the anhepatic phase of liver transplantation. Diabetes 49:450-456

19. UK Prospective Diabetes Study Group (1998) Intensive blood glucose control with sulphonylureas or insulin compared with conventional therapy and risk of complications in patients with Type 2 diabetes mellitus. UKPDS 33. Lancet 352:837-853

20. Jeandidier N, Selam JL, Renard E et al. (1996) Decreased severe hypoglycemia frequency during intraperitoneal insulin infusion using programmable implantable pumps. Evadiac Study Group. Diabetes Care 19:780

21. Dunn FL, Nathan DM, Scavini M, Selam JL, Wingrove TG (1997) Long-term therapy of IDDM with an implantable insulin pump. The Implantable Insulin Pump Trial Study Group. Diabetes Care 20:59-63

22. Osei K (1998) Post-transplantation hypoglycaemia in type 1 diabetic pancreas allograft recipients. Acta Diabetol 35:176-182

23. Leese G, Wwwang J, Broomhall J et al. (2002) Incidence of severe hypoglycaemia requiring emergency treatment in Type 1 and Type 2 diabetes: a population based study of health service resource use. Diabetic Medicine 19 [Suppl 2]:12

24. Ryder RJ, Owens DR, Hayes TM, Chatei MA, Bloom SR (1990) Unawareness of hypoglycaemia and ijnadequate hypoglycaemic counterregulation: no causla relationship with diabetic autonomic neuropathy. $\mathrm{Br}$ Med J 301: 783-787

25. White NH, Skor DA, Cruer PE, Levandorski LA, Bier DM, Santiago JV (1983) Identification of Type I diabetic patients at increased risk for hypoglycemia during intensive therapy. New Engl J Med 308:485-491

26. Burcelin R, Dolci W, Thorens B (2000) Glucose sensing by the hepatoportal sensor is GLUT2-dependent: in vivo analysis in GLUT2-null mice. Diabetes 49:1643-1648

27. Hevener AL, Bergman RN, Donovan CM (1997) Novel glucosensor for hypoglycemic detection localized to the portal vein. Diabetes 46:1521-1525

28. Hevener AL, Bergman RN, Donovan CM (2000) Portal vein afferents are critical for the sympathoadrenal response to hypoglycemia. Diabetes 49:8-12

29. Cardin S, Lavoie L, Gutierrez A, Bongbele J, Lavoie JM (1992) Hepatic vagotomy does not alter plasma insulin response to a low dose injection of glucose. Physiol Behav 52:237-240

30. Jackson PA, Cardin S, Coffey CS et al. (2000) Effect of hepatic denervation on the counterregulatory response to insulin-induced hypoglycemia in the dog. Am J Physiol Endocrinol Metab 279:1249-1257

31. Fujita S, Bergman RM, Donovan CM et al. (2001) Hypoglycemic detection in the protal vein is mediated by capsaicin-sensitive afferents. Diabetes 50 [Suppl 2]:A137

32. Gardemann A, Strulik H, Jungermann K (1986) A portalarterial glucose concentration gradient as a signal for an insulin-dependent net glucose uptake in perfused rat liver. FEBS Lett 202:255-259

33. Russek M, Lora-Vilchis MC, Islas-Chaires M (1980) Food intake inhibition elicited by intraportal glucose and adrenaline in dogs on a 22 hour-fasting/2 hour feeding schedule. Physiol Behav 24:157-156

34. Perseghin G, Regalia E, Battezzati A et al. (1997) Regulation of glucose homeostasis in humans with denervated livers. J Clin Invest 100:931-934

35. Heptulla RA, Tamborlane WV, Ma TY-Z, Rife F, Sherwin RS (2001) Oral glucose augments the counterregulatory response during insulin-induced hypoglycemia in humans. J Clin End Metab 86:645-648

36. Biggers DW, Myers SR, Neal D et al. (1989) Role of the brain in counterregulation of insulin induced hypoglycaemia in dogs. Diabetes 38:7-16

37. Frizzell RT, Jones EM, Davis SN et al. (1993) Counterregulation during hypoglycaemia is directed by widespread brain organs. Diabetes 42:1253-1261

38. Cane P, Artal R, Bergan RN (1986) Putative hypothalamic glucoreceptors play no essential role in the response to moderate hypoglycemia. Diabetes 35:268-277

39. Cane P, Haun CK, Evered J, Youn JH, Bergman RN (1988) Response to deep hypoglycemia does not involve glucoreceptors in carotid perfused tissue. Am J Physiol 255:680687

40. Ritter S, Dinh TT, Llwellyn Smith I (1998) Subgroups of hindbrain catecholamine neurons are selectively activated by 2-deoxy-D-glucose induced metabolic challenge. Brain Res 805:41-45

41. Song Z, Levin BE, McArdle JJ, Bakhos N, Routh VH (2001) Convergence of pre- and postsynaptic influences on glucosensing neurons in the ventromedial hypothalamic nucleus. Diabetes 50:2673-2681

42. Levin BE (2000) Glucose-regulated dopamine release from substantia nigra neurons. Brain Res 874:158-164

43. During MJ, Leone P, Davis KE, Kerr D, Sherwin RS (1995) Glucose modulates rat substantia nigra GABA re- 
lease in vivo via ATP-sensitive potassium channels. J Clin Invest 95:2403-2408

44. Minami S, Kamegai J, Sugihara H, Suzuki N, Higuchi H, Wakabayashi I (1995) Central glucoprivation evoked by administration of 2-deoxy-D-glucose induces expression of the c-fos gene in a subpopulation of neuropeptide $\mathrm{Y}$ neurons in the rat hypothalamus. Brain Res Mol Brain Res 33:305-310

45. Briski KP (1998) Glucoprivic induction of Fos immunoreactivity in hypothalamic dopaminergic neurons. Neuroreport 9:289-295

46. Jetton TL, Liang Y, Pettepher CC et al. (1994) Analysis of upstream glucokinase promoter activity in transgenic mice and identification of glucokinase in rare neuroendocrine cells in the brain and gut. Biol Chem 269:3641

47. Leloup C, Orosco M, Serradas P, Nicolaidis S, Penicaud L (1998) Specific inhibition of GLUT2 in arcuate nucleus by antisense oligonucleotides suppresses nervous control of insulin secretion. Brain Res Mol Brain Res 57:275-280

48. Dunn-Meynell AA, Rawson NE, Levin BE (1998) Distribution and phenotype of neurons containing the ATP-sensitive $\mathrm{K}+$ channel in rat brain. Brain Res 814:41-54

49. Grenhoff J, Johnson SW (1996) Sulfonylureas enhance GABAA synaptic potentials in rat midbrain dopamine neurones. Acta Physiol Scand 156:147-148

50. Guenat E, Seematter G, Philippe J, Temler E, Jequier E, Tappy L (2000) Counterregulatory responses to hypoglycaemia in patients with glucokinase gene mutations. Diabetes Metab 26:377-384

51. Spyer G, Hattersely A, Mitchell K, Ayres S, Amiel SA, Macleod K (2000) Is glucokinase the hypothalamic glucose sensor? British Diabetic Association 2000. Diabetic Medicine 17 [Suppl A]

52. Amiel SA, Archibald HR, Chusney G, Williams AJK, Gale EAM (1991) Ketone infusion lowers hormonal responses to hypoglycaemia: evidence for acute cerebral utilization of a non-glucose fuel. Clin Sci 81:189-194

53. Maran A, Cranston I, Lomas J, Macdonald IA, Amiel SA (1994) Protection by lactate of cerebral function during hypoglycaemia. Lancet ii 343:16-20

54. Evans ML, Matyka K, Lomas J et al. (1998) Reduced counterregulation during hypoglycemia with raised circulating non-glucose lipid substrates: evidence for regional differences in metabolic capacity in the human brain? J Clin Endocrinol Metab 83:2952-2959

55. Veneman T, Mitrakou A, Mokan M, Cryer P, Gerich J (1994) Effect of hyperketonemia and hyperlacticacidemia on symptoms, cognitive dysfunction and counterregulatory hormone responses during hypoglcyemia in normal humans. Diabetes 43:1311-1317

56. Deary IJ, Hepburn DA, MacLeod KM, Frier BM (1993) Partitioning the symptoms of hypoglycaemia using multi-sample confirmatory factor analysis. Diabetologia 36:771-777

57. Boyle PJ, Schwartz NS, Shah SD, Clutter WE, Cryer PE (1988) Plasma glucose concentrations at the onset of hypoglycemic symptoms in patients with poorly controlled diabetes and in nondiabetics. N Engl J Med 318:1487-1492

58. Spyer G, Hattersely AT, Macdonald IA, Amiel SA, MacLeod KM (2000) Hypoglycaemic conunterregulation at "normal" blood glucose concentrations in patients with well-controlled Type 2 diabetes. Lancet 356:1970-1974

59. Gold AE, MacLeod KM, Frier BM (1994) Frequency of severe hypoglycemia in patients with type I diabetes with impaired awareness of hypoglycemia. Diabetes Care 17: 697-703

60. Hepburn DA, Patrick AW, Eadington DW, Ewing DJ, Frier BM (1990) Unawareness of hypoglycaemia in insulin treated diabetic patients: prevalence and relationship to autonomic neuropathy. Diabetic Med 7:711-717

61. Diabetes Control and Complications Research Group (1993) The effect of intensive treatment of diabetes on the development and progression of long-term complications in insulin dependent diabetes mellitus. $\mathrm{N}$ Engl J Med 329:977-986

62. Lager I, Atvall S, Blohme G, Smith U (1986) Altered recognition of hypoglycaemic symptoms in Type 1 diabetes during intensified control with continuous subcutaneous insulin infusion. Diabetic Med 3:322-325

63. Amiel SA, Tamborlane WV, Simonson DC, Sherwin RS (1987) Defective glucose counterregulation after strict control of insulin-dependent diabetes mellitus. N Engl J Med 316:1376-1383

64. Amiel SA, Sherwin RS, Simonson DC, Tamborlane WV (1988) Effect of intensive insulin therapy on glycemic thresholds for counterregulatory hormone release. Diabetes 37:901-907

65. Maran A, Lomas J, Macdonald IA, Amiel SA (1995) Lack of preservation of higher brain function during hypoglycaemia in patients with intensively treated insulin dependent diabetes mellitus. Diabetologia 38:1412-1418

66. Heller SR, Cryer PE (1991) Reduced neuroendocrine and symptomatic responses to subsequent hypoglycaemia in non-diabetic humans. Diabetes 40:223-226

67. Davis SN, Shavers C, Mosqueda-Garcia R, Costa F (1997) Effects of differing antecedent hypoglycemia on subsequent counterregulation in normal humans. Diabetes 46: $1328-1335$

68. George E, Harris N, Bedford C, Macdonald IA, Hardisty CA, Heller SR (1995) Prolonged but partial impairment of the hypoglycaemic physiological response following shortterm hypoglycaemia in normal subjects. Diabetologia 38:1183-1190

69. Ovalle F, Fanelli CG, Paramore DS, Hershey T, Craft S, Cryer PE (1998) Brief twice-weekly episodes of hypoglycemia reduce detection of clinical hypoglycemia in type 1 diabetes mellitus. Diabetes 47:1472-1479

70. Fanelli CG, Paramore DS, Hershey T, Terkamp C, Ovalle F, Craft S, Cryer PE (1998) Impact of nocturnal hypoglycemia on hypoglycemic cognitive dysfunction in type 1 diabetes. Diabetes 47:1920-1927

71. Fanelli CG, Epifano L, Rambotti AM et al. (1993) Meticulous prevention of hypoglycemia normalizes the glycemic thresholds and magnitude of most of neuroendocrine responses to, symptoms of, and cognitive function during hypoglycemia in intensively treated patients with short-term IDDM. Diabetes 42:1683-1689

72. Cranston I, Lomas J, Maran A, Macdonald I, Amiel SA (1994) Restoration of hypoglycaemia awareness in patients with long-duration insulin-dependent diabetes. Lancet ii 344:283-287

73. Berlin I, Grimaldi A, Landault C et al. (1988) Lack of hypoglycemic symptoms and decreased beta-adrenergic sensitivity in insulin-dependent diabetic patients. J Clin Endocrinol Metab 66:273-278

74. Fritsche A, Stumvoll M, Grub M et al. (1998) Effect of hypoglycemia on beta-adrenergic sensitivity in normal and type 1 diabetic subjects. Diabetes Care 21:1505-1510

75. Dagogo-Jack S, Rattarasarn C, Cryer PE (1994) Reversal of hypoglycemia unawareness, but not defective glucose counterregulation, in IDDM. Diabetes 43:1426-1434

76. Meyer C, Grossmann R, Mitrakou A et al. (1998) Effects of autonomic neuropathy on counterregulation and awareness of hypoglycemia in type 1 diabetic patients. Diabetes Care 21:1960-1966 
77. Stephenson JM, Kempler P, Perin PC, Fuller JH (1996) Is autonomic neuropathy a risk factor for severe hypoglycaemia? The EURODIAB IDDM Complications Study. Diabetologia 39:1372-1376

78. Berlin I, Grimaldi A, Landault C et al. (1988) Lack of hypoglycemic symptoms and decreased beta-adrenergic sensitivity in insulin-dependent diabetic patients. J Clin Endocrinol Metab 66:273-278

79. Fanelli C, Pampanelli S, Lalli C et al. (1997) Long-term intensive therapy of IDDM patients with clinically overt autonomic neuropathy: effects on hypoglycemia awareness and counterregulation. Diabetes 46:1172-1181

80. Matyka KA, Wigg L, Pramming S, Stores G, Dunger DB (1999) Cognitive function and mood after profound nocturnal hypoglycaemia in prepubertal children with conventional insulin treatment for diabetes. Arch Dis Child 81:138-142

81. Boland E, Monsod T, Delucia M, Brandt CA, Fernando S, Tamborlane WV (2001) Limitations of Conventional Methods of Self-Monitoring of Blood Glucose: Lessons learned from 3 days of continuous glucose sensing in pediatric patients with type 1 diabetes. Diabetes Care 24:1858-1862

82. Takakura Y, Kuentzel SL, Raub TJ, Davies A, Baldwin SA, Borchardt RT (1991) Hexose uptake in primary cultures of bovine brain microvessel endothelial cells. I. Basic characteristics and effects of D-glucose and insulin. Biochim Biophys Acta 1070:1-10

83. Uehara Y, Nipper V, McCall AL (1997) Chronic insulin hypoglycemia induces GLUT-3 protein in rat brain neurons Am J Physiol 272:716-719

84. Boyle PJ, Nagy RJ, O'Connor AM, Kempers SF, Yeo RA, Qualls C (1994) Adaptation in brain glucose uptake following recurrent hypoglycemia. Proc Natl Acad Sci 91:93529356

85. Boyle PJ, Kempers SF, O’Connor AM, Nagy RJ (1995) Brain glucose uptake and unawareness of hypoglycemia in patients with insulin dependent diabetes mellitus. New Engl J Med 333:1726-1731

86. Brooks DJ, Gibbs JS, Sharp P et al. (1986) Regional cerebral glucose transport in insulin-dependent diabetic patients studied using [11C]3-O-methyl-D-glucose and positron emission tomography. J Cereb Blood Flow Metab 6:240-244

87. Segel SA, Fanelli CG, Dence CS et al. (2001) Blood-tobrain glucose transport, cerebral glucose metabolism, and cerebral blood flow are not increased after hypoglycemia. Diabetes 50:1911-1917

88. Amiel SA, Simonson DC, Tamborlane WV, DeFronzo RA, Sherwin RS (1987) Rate of glucose fall does not affect counterregulatory hormone responses to hypoglycemia in normal and diabetic humans. Diabetes:518-522

89. Mitrakou A, Ryan C, Veneman T et al. (1991) Hierarchy of glycemic thresholds for counterregulatory hormone secretion, symptoms and cerebral dysfunction. Am J Physiol 260:67-74

90. Hvidberg A, Fanielli CG, Hershey T, Terkamp C, Craft S, Cryer PE (1996) Impact of recent antecedent hypoglycemia on hypoglycemic cognitive dysfunction in non diabetic humans. Diabetes 45:1030-1036

91. Rosenthal JM, Amiel SA, Yaguez L et al. (2001) The effect of acute hypoglycemia on brain function and activation: a functional magnetic resonance imaging study. Diabetes 50:1618-1626

92. Molina PE, Eltayeb K, Hourani H et al. (1993) Hormonal and metabolic effects of neuroglucopenia. Brain Res 614:99-108

93. Borg WP, During MJ, Sherwin RS, Borg MA, Brines ML, Shulman GI (1994) Ventromedial hypothalamic lesions in rats suppress counterregulatory responses to hypoglycemia. J Clin Invest 93:1677-1682

94. Borg WP, Sherwin RS, During MJ, Borg MA, Shulman GI (1995) Local ventromedial hypothalamus glucopenia triggers counterregulatory hormone release. Diabetes 44: 180-184

95. Borg MA, Sherwin RS, Borg WP, Tamborlane WV, Shulman GI (1997) Local ventromedial hypothalamus glucose perfusion blocks counterregulation during systemic hypoglycemia in awake rats. J Clin Invest 99:361-365

96. Borg MA, Borg WP, Tamborlane WV, Brines ML, Shulman GI, Sherwin RS (1999) Chronic hypoglycemia and diabetes impair counterregulation induced by localized 2deoxy-glucose perfusion of the ventromedial hypothalamus in rats. Diabetes 48:584-587

97. Tkacs NC, Dunn-Meynell AA, Levin BE (2000) Presumed apoptosis and reduced arcuate nucleus neuropeptide $\mathrm{Y}$ and pro-opiomelanocortin mRNA in non-coma hypoglycemia. Diabetes 49:820-826

98. Davis SN, Shavers C, Davis B, Costa F (1997) Prevention of an increase in plasma cortisol during hypoglycemia preserves subsequent counterregulatory responses. J Clin Invest 100:429-438

99. Cranston I, Reed LJ, Marsden PK, Amiel SA (2001) Changes in regional brain ${ }^{18} \mathrm{~F}$-fluorodeoxyglucose uptake at hypoglycemia in Type 1 diabetic men associated with hypoglycemia unawareness and counterregulatory failure. Diabetes 50:2329-2336

100. Fery F, Plat L, Borne P van de, Cogan E, Mockel J (1999) Impaired counterregulation of glucose in a patient with hypothalamic sarcoidosis. N Engl J Med 340:852-856

101. Shorr RI, Ray WA, Daugherty JR, Griffin MR (1997) Incidence and risk factors for serious hypoglycemia in older persons using insulin or sulfonylureas. Arch Intern Med 157:1681-1686

102. Chan TY, Lee KK, Chan AW, Critchley JA (1996) Utilization of antidiabetic drugs in Hong Kong: relation to the common occurrence of antidiabetic drug induced hypoglycemia amongst acute medical admissions and the relative prevalence of NIDDM. Int J Clin Pharmacol Ther 34:43-46

103. Stahl M, Berger W (1999) Higher incidence of severe hypoglycaemia leading to hospital admission in type 2 diabetic patients treated with long acting versus short acting sulphonylureas. Diabet Med 16:586-590

104. Jaap AJ, Jones GC, McCrimmon RJ, Deary IJ, Frier BM (1998) Perceived symptoms of hypoglycaemia in elderly type 2 diabetic patients treated with insulin. Diabet Med 15:398-401

105. Matyka K, Evans M, Lomas J et al. (1997) Altered hierarchy of protective responses against severe hypoglycemia in normal aging in healthy men. Diabetes Care 20:135141

106. Amiel SA, Simonson DC, Sherwin RS, Lauritano AA, Tamborlane WV (1987) Exaggerated epinephrine responses to hypoglycemia in normal and insulin-dependent diabetic children. J Pediatr 110:832-837

107. McCrimmon RJ, Gold AE, Deary IJ, Kelnar CJH, Frier BM (1995) Symptoms of hypoglcyaemia in children. Diabetes Care: 18:858-861

108. Rovet JF, Ehrlich RM (1999) The effect of hypoglycemic seizures on cognitive function in children with diabetes: a 7-year prospective study. J Pediatr 134:503-506

109. Langan SJ, Deary IJ, Hepburn DA, Frier BM (1991) Cumulative cognitive impairment following recurrent severe hypoglycaemia in adult patients with insulin-treated diabetes mellitus. Diabetologia 34:337-344 